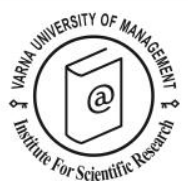

\title{
Maritime Tourism: Modelling consumer behaviour and its managerial implications
}

\author{
Yen E. Lam-González ${ }^{1}$
}

Received: 25/02/2019

\begin{abstract}
1 TIDES, Tourism and Sustainable Development Institute. University of Las Palmas de Gran Canaria. Tafira Campus, Building E-Floor 0, Saulo Torón, 4 - Las Palmas de GC, Spain. Postcode 35017 tel:+34928451033, E-mail: yen.lam@ulpgc.es
\end{abstract}

Coordinating editor: Faizan Ali

Supervisors: Carmelo J. León González and Matias M. Gonzalez Hernandez

Institution awarding the Ph. D. Degree: University of Las Palmas de Gran Canaria.

Date of defence: 18/09/2018

Citation: Lam-González, Y. (2019) Maritime Tourism: Modelling consumer behaviour and its managerial implications. Doctoral Dissertation Summary. European Journal of Tourism Research 23, pp. 208-211

\section{Goals and objectives of the dissertation}

This dissertation is based on a collection of four papers, corresponding to the different phases of the doctoral research. The first work aims to offer a rigorous review of the publications on maritime tourism over the last decade, and identifies gaps regarding the study of the behaviour of tourists from this market niche. Along these lines, the following three papers aim to propose and validate universal models for better prediction of the behaviour of tourists travelling for maritime recreation and sports. More specifically, the three models examine i) the determinants of on-site individual expenditure of nautical tourists, ii) factors influencing the satisfaction of yachtsmen with marina ports of call, and finally iii) the impact of climate perceived comfort on nautical tourists' expenditure decisions and satisfaction with the destination visited.

\section{Methodology}

First, boundaries for the conceptual definition of nautical tourism as a tourism segment were defined, followed by a systematic and metaanalytic review of high impact scientific articles. The review was conducted in four steps, for a ten-year period (2008-2017). The counting methods were applied by cases and fractional, and scientific productivity rankings were drawn up per journal, centre and author. During the meta-analysis phase, the individual statistical results, and the variables subjected to causal models of prediction of consumer behaviour were interpreted.

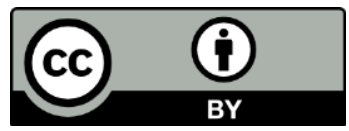

208
This work is licensed under the Creative Commons Attribution 4.0 International (CC BY 4.0). To view a copy of this license, visit https://creativecommons.org/licenses/by/4.0/ 
The second article proposes an explanatory model of the determinants of the individual expenditure made by the tourist during the stay at the destination, including variables at the psychographic level. Secondly, it aims to verify if the determinants of spending vary among tourists with different patterns of nautical behaviour in the destination. To do this, an ordinal logistic regression model is formulated. The model is developed for four sample sub-groups with different nautical behaviour patterns. The data was obtained from a survey of the demand that was carried out in Gran Canaria and Lanzarote destinations between 2014 and 2016, which allowed the construction of a sample of 327 nautical tourists.

The third article proposes a model of structural equations to explain the satisfaction of the nautical tourist with the stop-over marina. Twelve research hypotheses are proposed, relating to the services of the marina, the destination attributes, motivations, and the destination chosen for the call. The main instrument was the survey and the fieldwork is carried out in the main ports of call of the Atlantic region, located in the destinations of Gran Canaria, Lanzarote (Spain), Agadir (Morocco), and Mindelo (Cape Verde). The sample consisted of 243 yachtsmen mooring their vessels in these destinations.

The fourth paper proposes and empirically tests a structural model to measure the effect of climate perceived comfort on tourists' onsite consumption, expenditure and satisfaction with the destination. Ten hypotheses were formulated, involving variables such as i) the tourist satisfaction with climatic conditions, ii) the number of nautical activities carried out during the stay, iii) the total expenditure of the tourist during the visit, and iv) the tourist satisfaction with the nautical tourism products and services on offer at the destination. The model was validated utilising empirical data from 255 nautical tourists visiting Cape Verde in 2017. A confirmatory factor analysis was also employed to define the constructs in the structural equation.

\begin{abstract}
Results
Thanks to the first paper it has been possible to clarify the specific needs of scientific knowledge about maritime tourism, and provide information on the journals that are most suitable to disseminate new contributions. At this stage, we measure the productivity of the last decade, and identify regional differences between publications from European, American or Asian institutions. It is worth noting that the European academic community shows signs of fragmentation and little stability in publications on this segment. It also demonstrates that the current research needs to incorporate models for better prediction on decision processes, and on the determinants of the tourist experience.
\end{abstract}

Paper 2 shows that advertising and recommendations from friends show the greatest potential in increasing tourist expenditure. Internet is revealed as being also a very powerful tool that encourages greater tourist spending during the visit. It is discovered that factors determining spending vary among tourists with different patterns of nautical behaviour in the destination. It was found that repeating tourists usually spend more, however, many visits in a row to the same destination can generate an inverse effect, and in these cases it is convenient that tourists have interspersed experiences at other nautical destinations, to stimulate spending at the main destination. It has also demonstrated the importance of image and satisfaction which were always found with direct and positive effect on spending.

Paper 3 proves that the image and quality of the services offered by the marina is not the only element that influences satisfaction with the marinas. The destination chosen to moor the boat, and the opinions that these tourists have about the nautical tourism offer at the destination, also have an impact on the satisfaction with the nautical installations. The results suggest that establishing policies for nautical tourism ports has to facilitate the consumption of other maritime activities at the destination. Managers must be also concerned about the security policy at the 
destination, and should clearly inform their users of the same. Also, as the marina represents more than just a mooring facility, it is easy to understand that sea lovers want to experience a "marina" as a platform for the development of nautical tourism in all its modalities.

In the last paper, it was concluded that nautical tourists demand more maritime activities at the destination when they perceive the more suitable climatic conditions. In addition, there is a high impact of this consumption on the individual expenditure and the satisfaction of the nautical tourist. Consequently, all nautical destinations must not only design a supply of products and experiences to be coherent with their natural features, but they also need to provide an improved climatic experience for the tourist, by adapting climatic-meteorological information to their needs. Therefore, planning should not only exploit the advantages of climate, but also attempts to inform about more benevolent microclimates that match tourists' expectations more closely.

\section{Theoretical conclusions}

The main contributions of the research are that i) it provides a wider understanding of the behaviour of nautical tourists; ii) it advances in the study of explanatory variables scarcely analysed in the literature on tourism spending and satisfaction, and iii) it empirically validates three explanatory models of spending and satisfaction with a greater explanatory power with respect to previous studies. The research focuses on the part of spending that takes place at the destination, which allows generating more precise recommendations for tourism managers, as when the total expenditure of tourists is analysed, the conclusions do not allow to distinguish the challenges for the specific destination.

\section{Practical application of the dissertation}

The work provides relevant information, and allows the elaboration of useful recommendations for destinations managers and the business sector, in support of economic impact strategies and the positioning in the international nautical tourism market. It is advisable to work on the creation of institutional research alliances, which allow identifying and organising resources and capacities with a common purpose. This is very useful to build a robust holistic knowledge base on the segment in Europe.

The study has allowed us to understand that research on tourist spending ideally should be segmented by tourist activity, since tourists behave different even if they have the same travel motivation. Also, it was confirmed that loyalty has a direct impact on expenditure, however, working on joint promotion strategies with competing destinations is also convenient, and should form part of the agenda for nautical tourism promoters. It is essential that managers be aware of the benefits that provide coopetition strategies between destinations of the same specialisation. In the case of the Canary Islands, for example, combining nautical tourism packages with Tunisia and Agadir shows a high probability of success for the market niches with preference for watercraft and board sports.

Regarding the port and marina business, it has been proven that when the facility is not committed to the sector, by providing spaces and promoting the nautical potential of the destination, or generating opportunities for companies in their environment to promote other maritime activities, the users' satisfaction with the installations is affected. It is a challenge for the managers to merge the marina with its surroundings, with nature, the nautical culture and the authenticity of the destination, generating a space of natural transition between sea and land. The marinas have to be seen as spaces to promote the potential of the destination and the nautical tourism companies of the region where they are located.

Finally, proving that climatic comfort perception is a dominant factor that explains consumption, expenditure and satisfaction of nautical tourists, represent a huge challenge 
for a competitive nautical destination. In order to assure a positive climatic experience in nautical tourism, destinations need to: i) improve the climatic-meteorological information of the destination to facilitate tourist's choice processes and travel planning; and ii) design climate services that are capable of guiding the tourist at the appropriate time to the areas where activities can be carried out in the best possible conditions. This is especially important on islands, because the relevant climatic conditions for nautical activities do vary sometimes significantly- along the coastline, and between moments in time. In this context, climate services constitute a mean to generate technological innovation, thus increasing competitiveness while promoting awareness of Climate Change in the society.

\section{Content of the dissertation}

\section{Abstract of Chapter 1}

This article carries out a systematic review of publications on maritime tourism during the last ten years (2008-2017), with the purpose of quantifying the number of investigations, and analysing the involvement of centres, researchers and European journals in the generation and dissemination of knowledge. In addition, a meta-analysis of the empirical works is carried out, evaluating the complexity and diversity of the statistical methods and models used to predict nautical consumers' behaviour. It also aims to contribute to bridge the science-policy interface in nautical tourism management, thus raising the effectiveness of applied research for the design of better marketing and positioning strategies of nautical destinations.

\section{Abstract of Chapter 2}

This research aims to discover the determinants of spending by nautical tourists at the destination. For this purpose, 327 nautical tourists were surveyed at the end of their visit to the Canary Islands, and a logistic regression model was validated, discovering that the factors capable of modifying the tourist's expenditure vary according to the nautical behaviour patterns at the destination. It has been shown that the affection generated towards the destination, as well as the loyalty of the nautical tourist, have a positive effect on spending, although in certain circumstances it is convenient to motivate tourists to visit other destinations.

\section{Abstract of Chapter 3}

This research aims to explain yachtsmen's satisfaction with marina ports of call. Data from questioning 402 European sailors while crossing the Atlantic between 2013 and 2015 were utilised to validate a structural model involving 12 hypotheses. Findings indicate that the destination choice has significant influence on satisfaction. In addition, the nautical experience provided by the destination has great importance in understanding and predicting their evaluation of the marina. The findings provide the opportunity for developing recommendations for tourism managers, in the attempt to contribute to a more sustainable development and growth of the sector.

\section{Abstract of Chapter 4}

Climatic conditions may influence undertaking nautical activities at destinations. By using data collected from 255 nautical tourists in Cape Verde, this article proposes and empirically tests a structural model to measure the effect of climate comfort perceived by tourists on the consumption of activities and expenditure decisions. The study finds that satisfaction with climate is the main determinant of the nautical activities consumed by tourists. In addition, nautical consumption mediates the effects of climate on tourist satisfaction and on-site expenditure. The results highlight the importance of the design of climate-oriented services for improving nautical tourism experiences.

\section{Acknowledgment}

This work was funded by the Operational Programme "Spain - External Borders 20082013 Cross-Border Cooperation Programme" ERDF, EC, in its third call for projects, through a research grant with reference 0077 NAUCAMNET_3 "Sostenibilidad integrada de la Cooperación Náutica entre Canarias y la región Souss Massa Draa" 